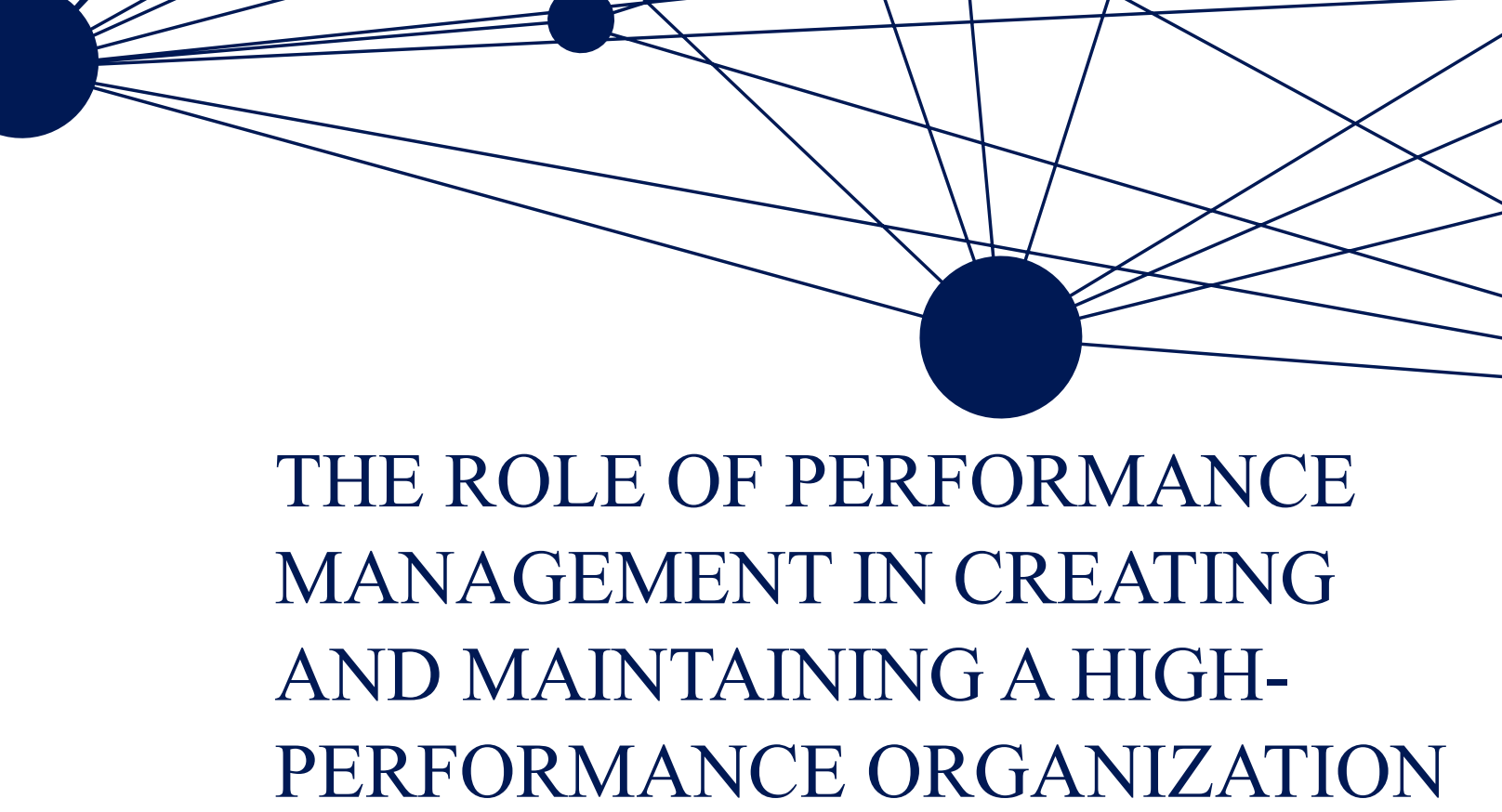

\author{
ANDRÉ A. DE WAAL・BÉATRICE I.J.M. VAN DER HEIJDEN
}

\begin{abstract}
There is still a good deal of confusion in the literature about how the use of a performance management system affects overall organizational performance. Some researchers find that performance management enhances both the financial and non-financial results of an organization, while others do not find any positive effects or, at most, ambiguous effects. An important step toward getting more clarity in this relationship is to investigate the role performance management plays in creating and maintaining a high-performance organization (HPO). The purpose of this study is to integrate performance management analysis (PMA) and high-performance organization (HPO). A questionnaire combining questions on PMA dimensions and HPO factors was administered to two European-based multinational firms. Based on 468 valid questionnaires, a correlation analysis was performed on the PMA dimensions and the HPO factors in order to test the impact of performance management on the factors of high organizational performance. The results show strong and significant correlations between all the PMA dimensions and all the HPO factors, indicating that a performance management system that fosters performance-driven behavior in the organization is of critical importance to strengthen overall financial and non-financial performance.
\end{abstract}

Keywords: Performance management, performance-driven behavior, performance management analysis, high-performance organization

Research on the effects of performance management on organizational performance has produced conflicting results (Neely, 2005), suggesting that the impact of performance management is still not well understood (Pavlov \& Bourne, 2011). A recent review by de Waal and Kourtit (2013) lists both financial advantages (revenue and profits increase while costs decrease) and non-financial advantages (improved communication, closer collaboration, better knowledge sharing, stronger focus on what really matters and on the achievement of results, better strategic alignment, higher operational efficiency, higher commitment of organizational members, more innovation, higher employee and customer satisfaction, and a strengthened organizational reputation). On the other hand, the same review also found disadvantages of using a performance management system, including information overload, too much subjectivity, too much financial and backward-looking information, and an expensive, bureaucratic management approach.

Rangone (1997) remarked that the link between the use of performance measures and organizational effectiveness has been widely recognized but that explanations for this relationship are constrained by the lack of a clear theoretical foundation. Almost two decades later, lack of theory still seems to be an issue, judging from Brudan's (2010: 110) lament that "the lack of standards regarding the definition, classification and usage of specific tools make both research and application of performance management principles difficult." Pavlov and Bourne (2011) pointed out that the literature thus far has not demonstrated how performance 
management systems are linked to overall organizational performance. Choong (2014) takes this viewpoint even further when he says that most researchers in the field of performance measurement have not articulated the performance management system as a complete entity, and because of this we do not have a clear understanding of the interaction of activities of sub-systems within the organization. Moreover, according to Taticchi, Balachandran, and Tonelli (2012), achieving this understanding might be hampered by the fact that there is still a limited understanding of the cause-effect relationships between the performance management system and organizational results.

Pavlov and Bourne (2011: 105) concluded that there is still "a black box" that separates performance management from organizational outcomes and that "opening this black box would allow researchers to elucidate the process through which performance management affects performance..." and "in order to understand the mechanism of the impact of performance management on performance, one needs to understand how performance management affects these organizational processes." An important step toward opening the black box is to investigate the role performance management plays in creating and maintaining a high-performance organization (HPO). An HPO is defined as an organization that achieves financial and non-financial results that exceed those of its peer group over a period of five years or more, by focusing in a disciplined way on what really matters to the organization (de Waal, 2012). In order to create a sustainable HPO, managers and employees alike have to behave in such a way that the objectives and goals of the organization are achieved on a high level. In practice, this implies that the organization's performance management systems have to be designed in such a way that they provide constructive information and feedback so that organization members can behave in a performance-driven manner.

In this article, we examine the relationship between performance management and the high-performance organization using Performance Management Analysis (de Waal, 2010) and the HPO framework (de Waal, 2012). The goal of the empirical study presented here is to evaluate which dimensions of performance management help to create a high-performance organization. This is important to know because the outcomes of such research can be used by organizations to shape their performance management systems which, in turn, will help them in their quest to become and stay a high-performance organization. The article is organized as follows. First, we describe the Performance Management Analysis and the High-Performance Organization frameworks and the theoretical link between them. Then we describe a worldwide study of two companies with roughly comparable performance management systems. Based on the study findings, we offer several recommendations for future research and practice.

\section{PERFORMANCE MANAGEMENT ANALYSIS}

A technique that can be used to assess the impact of performance management in an organization is the Performance Management Analysis (PMA) (de Waal, 2010). The PMA makes a distinction between structural and behavioral aspects of performance management. The structural aspect refers to the system's architecture, which needs to be in place in order to use performance management. This usually involves determining Critical Success Factors (CSF) and Key Performance Indicators (KPI) as well as designing a Balanced Scorecard (Kaplan \& Norton, 1996). The behavioral aspect refers to the organization's members and their use of the performance management system. The PMA is based on the principle that the two aspects of performance management, structural and behavioral, need to be given equal attention in order to establish a performance-driven organization. There are many things that can be measured and reported in an organization, but they will be of little value if organization members do not use this information to improve performance. Conversely, goodwill of organization members does not count for much when they cannot access the performance information needed to display performance-driven behavior. The PMA enables an organization to actually assess the degree of performance-driven behavior (Elzinga, Albronda, \& Kluijtmans, 2009). 
The PMA is a comprehensive survey instrument currently divided into nine dimensions. These dimensions are briefly described below (for a more detailed description see Appendix 1).

1. Responsibility structure (structural dimension): A clear parenting style; tasks and responsibilities have been defined and are applied consistently at all management levels.

2. Content (structural): Organization members use a set of financial and non-financial performance information that has a strategic focus (e.g., CSFs and KPIs).

3. Integrity (structural): The performance information is reliable, timely, and consistent.

4. Manageability (structural): Management reports and performance management systems are user-friendly, and more detailed performance information is easily accessible through ICT systems.

5. Alignment (structural): Other management systems, such as the human resource management system, are aligned with performance management, so what is important to the organization is regularly evaluated and rewarded.

6. Accountability (behavioral): Organization members feel responsible for the results of the KPIs of both their own responsibility areas and the organization as a whole.

7. Management style (behavioral): Senior management is proactive and involved in the performance of organization members and stimulates an improvement culture. At the same time, management consistently confronts organization members who are underperforming.

8. Action orientation (behavioral): Performance information is integrated into the daily activities of organization members in such a way that problems are immediately addressed, and corrective or preventive actions are taken.

9. Communication (behavioral): Communication about the results (top-down and bottom-up) takes place at regular intervals as well as the sharing of knowledge and performance information between organizational units.

\section{THE HIGH-PERFORMANCE ORGANIZATION}

The HPO framework is based on a literature review of 290 academic and practitioner publications about high-performance organizations (de Waal, 2012; de Waal et al., 2014). Out of each of the reviewed publications, elements were identified that the authors regarded as essential to becoming an HPO. Because the authors of the various scholarly contributions often used different terminology, the identified elements were grouped into categories that constituted possible HPO characteristics. For each of the possible HPO characteristics, its weighted importance was calculated (i.e., the number of times that it was mentioned in the publications). Lastly, the possible HPO characteristics with the highest weighted importance were included in an HPO questionnaire that was administered worldwide and included more than 3,200 respondents. In this questionnaire, respondents graded (on a scale of 1 to 10) how well they thought their organizations were performing with respect to the HPO characteristics. They also graded their performance results compared to their peer group of organizations. By performing a statistical analysis, we identified 35 characteristics that had the strongest correlation with organizational performance. High-performing organizations scored higher on the 35 HPO characteristics in comparison with low-performing organizations. This means that organizations that pay more attention to these 35 characteristics achieve better results than their peers in every industry, sector, and country across the world. Conversely, organizations that scored low on the characteristics appeared to rank at the bottom of their industry, performance wise (de Waal, 2012).

A factor analysis, performed during the statistical analysis, resulted in the determination of five distinct HPO factors. These five factors are described below (for a more detailed description see Appendix 2).

1. Management Quality. In an HPO, belief and trust in others and fair treatment are encouraged. Managers are trustworthy; behave with integrity; show commitment, enthusiasm, and respect; and have a decisive, action-oriented decision-making style. Management holds people accountable for their results by maintaining clear 
accountability for performance. Values and strategy are communicated throughout the organization so that everyone knows and embraces these organizational features.

2. Openness and Action-Orientation. HPOs have an open culture, which means that management values the opinions of employees and involves them in important organizational processes. Making mistakes is allowed and is regarded as an opportunity to learn. Employees spend a lot of time on dialogue, knowledge exchange, and learning in order to develop new ideas aimed at increasing their performance and making the organization performance-driven. Managers are personally involved in experimentation, thereby fostering receptivity to change in the organization.

3. Long-Term Orientation. An HPO grows through partnerships with suppliers and customers so that long-term commitment is extended to all stakeholders. Job vacancies are filled by high-potential internal candidates, and people are encouraged to become leaders. The HPO creates a safe and secure workplace (both physical and mental) and lays off people only as a last resort.

4. Continuous Improvement and Renewal. An HPO compensates for struggling strategies by renewing them and making them unique. The organization continuously improves, simplifies and aligns its processes, and develops new products and services, thereby creating sources of competitive advantage to respond to market changes. Furthermore, the HPO manages its core competencies efficiently and outsources noncore competencies.

5. Workforce Quality. An HPO assembles a diverse and complementary management team and workforce with maximum work flexibility. The workforce is trained to be resilient and flexible. Employees are encouraged to develop their skills to accomplish extraordinary results and are held responsible for their performance. As a result, creativity increases, leading to better results.

The HPO framework is built upon the idea that there is a direct and positive relationship between the identified HPO factors and organizational performance: the higher the HPO scores, the better the performance of the organization, and vice versa. An organization can empirically investigate its HPO status by having management and employees fill in an HPO questionnaire and calculating the average scores on the HPO factors. Our own analyses have shown that several characteristics have a direct relation to performance management:

- The organization is performance-driven

- Management focuses on achieving results

- Everything that matters to the organization's performance is explicitly reported

- Both financial and non-financial information is reported to organization members

- Management inspires and coaches organization members to achieve extraordinary results.

Thus, theoretically, a strong correlation between performance management and a highperformance organization can be expected. To evaluate whether this is the case in a particular organization, the performance management system of the organization has to be empirically tested on its ability to support the organization in achieving high performance. This can be accomplished by relating the HPO framework to the PMA.

\section{THEORETICAL RELATIONSHIP BETWEEN PMA AND HPO}

Relating the PMA and the HPO frameworks, the first obvious link is in the HPO factor Continuous Improvement and Renewal which contains two characteristics that have to do directly with performance measurement: "In the organization everything that matters to performance is explicitly reported," and "In the organization both financial and non-financial information is reported to organization members." The first characteristic matches with the PMA dimension Content while the second characteristic matches with the PMA dimension Manageability. Further, other HPO factors also show theoretical links with PMA. According to the HPO factor Management Quality, in organizations that score high on this, managers are results-oriented, and they deal decisively with non-performers, which matches with the PMA dimensions Responsibility Structure, Accountability, and Management Style. Regarding the HPO factor Workforce Quality, in organizations that score high on this, employees feel 
responsible for their results, which also matches with the PMA dimension Accountability. Regarding the HPO factor Openness and Action-Orientation, in organizations scoring high on this, employees spend a lot of time on dialogue, knowledge exchange, and learning in order to make the organization more performance-driven. This matches with the PMA dimensions Action Orientation and Communication. Finally, for the HPO factor Long-Term Orientation, in organizations with a high score on this, there is no obvious link with PMA. However, the argument could be made that an effective performance management system helps maintain and safeguard the sustainability of the organization and thereby its long-term survival.

\section{RESEARCH METHOD}

In the present study, the PMA and HPO frameworks were combined into one questionnaire, which was then distributed to two multinational companies operating in Europe. One company is a bank of which the Dutch branch offices participated. The other company is a car rental agency of which the sales offices in five countries (Netherlands, UK, Spain, Germany, France) participated. The performance management systems of both companies were roughly comparable in the sense that: (a) both systems were designed to capture information from multiple units which was then aggregated to the company level; (b) in both companies standardized financial and non-financial information was collected and reported, in the form of key performance indicators (KPIs), per month and per quarter, per country, and per office; (c) many of the KPIs were the same for both companies, and in addition to the obvious financial indicators, non-financial indicators such as customer satisfaction and employee satisfaction were applied in both companies as well; and (d) the KPI reports were discussed every month at both companies. As such, the performance management systems and their usage were quite homogeneous for both multinational companies.

\section{Sample and Procedure}

In the questionnaire, managers and employees of each organization were asked to rate their organization on the $35 \mathrm{HPO}$ characteristics and the nine PMA characteristics, on a scale of 1 (the organization does not satisfy the characteristic at all) to 10 (the organization satisfies the characteristic completely). The scores of all respondents were averaged for the five HPO factors and the nine PMA dimensions. In total, 468 valid questionnaires were received, out of a possible total of 2,024 respondents, resulting in a response rate of 23.1 percent. Using the final valid sample of 468 respondents, a correlation analysis was performed on the HPO factors and the PMA dimensions.

\section{Measures}

The reliability of the PMA dimensions and the HPO factors, calculated as Cronbach's alpha, is shown in Table 1. As can be seen, all PMA dimensions and all HPO factors (with the exception of Workforce Quality) show a high reliability. This means that a relevant correlation analysis can be performed.

Table 1. Reliabilities of PMA Dimensions and HPO Factors

\begin{tabular}{|l|c|c|}
\hline Dimensions/Factors & Number of Items & Cronbach's Alpha \\
\hline PMA dimensions & 4 & .732 \\
\hline Responsibility structure & 5 & .722 \\
\hline Content & 5 & .872 \\
\hline Integrity & 5 & .823 \\
\hline Manageability & 5 & .709 \\
\hline Alignment & 5 & .881 \\
\hline Accountability & 5 & .819 \\
\hline Management style & 5 & .823 \\
\hline Action orientation & 5 & .804 \\
\hline Communication & 5 & \\
\hline
\end{tabular}




\begin{tabular}{|l|c|c|}
\hline \multicolumn{1}{|l|}{ HPO factors } \\
\hline Management Quality & 12 & .897 \\
\hline Openness and Action-Orientation & 6 & .783 \\
\hline Long-Term Orientation & 4 & .818 \\
\hline Continuous Improvement & 8 & .877 \\
\hline Workforce Quality & 4 & .651 \\
\hline
\end{tabular}

\section{FINDINGS}

Based on their theoretical relationship, strong correlations between the PMA dimensions and the HPO factors were predicted. As can be seen in Table 2, there are strong and significant correlations (one-tailed Pearson's $r$ correlations) between all the PMA dimensions and all the HPO factors, indicating that a performance management system that fosters performancedriven behavior is indeed of critical importance to creating and sustaining a high-performance organization.

Table 2. Correlations Between the PMA Dimensions and the HPO Factors

\begin{tabular}{|l|c|c|c|c|c|}
\hline $\begin{array}{l}\text { Factors/ } \\
\text { Dimensions }\end{array}$ & $\begin{array}{c}\text { Management } \\
\text { Quality }\end{array}$ & $\begin{array}{c}\text { Openness } \\
\text { and Action } \\
\text { Orientation }\end{array}$ & $\begin{array}{c}\text { Long-Term } \\
\text { Orientation }\end{array}$ & $\begin{array}{c}\text { Continuous } \\
\text { Improvement }\end{array}$ & $\begin{array}{c}\text { Workforce } \\
\text { Quality }\end{array}$ \\
\hline $\begin{array}{l}\text { Responsibility } \\
\text { Structure }\end{array}$ & .499 & .414 & .403 & .469 & .400 \\
\hline Content & .473 & .465 & .443 & .520 & .396 \\
\hline Integrity & .402 & .437 & .420 & .526 & .340 \\
\hline Manageability & .401 & .431 & .370 & .381 & .375 \\
\hline Alignment & .477 & .510 & .381 & .523 & .397 \\
\hline Accountability & .503 & .482 & .449 & .305 & .367 \\
\hline $\begin{array}{l}\text { Management } \\
\text { Style }\end{array}$ & .456 & .397 & .307 & .329 & .312 \\
\hline $\begin{array}{l}\text { Action } \\
\text { Orientation }\end{array}$ & .353 & .353 & .402 & .487 & .418 \\
\hline Communication & .440 & .547 & & & .340 \\
\hline
\end{tabular}

Note: All correlations are significant at the .01 level.

The results depicted in Table 2 can be rearranged to show which PMA dimensions have the strongest impact on which HPO factors. Table 3 shows the results of this rearrangement in qualitative terms. 
Table 3. Order of Impact of the PMA Dimensions on Each HPO Factor

\begin{tabular}{|c|c|c|c|c|c|}
\hline $\begin{array}{l}\text { Factors/ } \\
\text { Order of } \\
\text { Impact }\end{array}$ & $\begin{array}{l}\text { Management } \\
\text { Quality }\end{array}$ & $\begin{array}{l}\text { Openness } \\
\text { and Action- } \\
\text { Orientation }\end{array}$ & $\begin{array}{l}\text { Long-Term } \\
\text { Orientation }\end{array}$ & $\begin{array}{l}\text { Continuous } \\
\text { Improvement }\end{array}$ & $\begin{array}{l}\text { Workforce } \\
\text { Quality }\end{array}$ \\
\hline 1 & Accountability & Communication & Accountability & Accountability & Accountability \\
\hline 2 & $\begin{array}{l}\text { Responsibility } \\
\text { structure }\end{array}$ & Alignment & Content & Integrity & Communication \\
\hline 3 & Alignment & Accountability & Integrity & Content & $\begin{array}{l}\text { Responsibility } \\
\text { structure }\end{array}$ \\
\hline 4 & Content & Content & $\begin{array}{l}\text { Responsibility } \\
\text { structure }\end{array}$ & Communication & Alignment \\
\hline 5 & $\begin{array}{l}\text { Management } \\
\text { style }\end{array}$ & Integrity & Communication & Manageability & Content \\
\hline 6 & Communication & Manageability & Alignment & $\begin{array}{l}\text { Responsibility } \\
\text { structure }\end{array}$ & Manageability \\
\hline 7 & Integrity & $\begin{array}{l}\text { Responsibility } \\
\text { structure }\end{array}$ & Manageability & Alignment & $\begin{array}{l}\text { Management } \\
\text { style }\end{array}$ \\
\hline 8 & Manageability & $\begin{array}{l}\text { Management } \\
\text { style }\end{array}$ & $\begin{array}{l}\text { Action } \\
\text { orientation }\end{array}$ & $\begin{array}{l}\text { Action } \\
\text { orientation }\end{array}$ & Integrity \\
\hline 9 & $\begin{array}{l}\text { Action } \\
\text { orientation }\end{array}$ & $\begin{array}{l}\text { Action } \\
\text { orientation }\end{array}$ & $\begin{array}{l}\text { Management } \\
\text { style }\end{array}$ & $\begin{array}{l}\text { Management } \\
\text { style }\end{array}$ & $\begin{array}{l}\text { Action } \\
\text { orientation }\end{array}$ \\
\hline
\end{tabular}

Using the information shown in Table 3, a ranking can be made of the PMA dimensions according to their impact on the HPO factors (see Table 4).

Table 4. Impact Ranking of the PMA Dimensions

\begin{tabular}{|l|l|l|}
\hline Order of Impact & PMA Dimension & Type of Dimension \\
\hline 1 & Accountability & Behavioral \\
\hline 2 & Communication & Behavioral \\
\hline 3 & Content & Structural \\
\hline 4 & Responsibility Structure & Structural \\
\hline 5 & Alignment & Structural \\
\hline 6 & Integrity & Structural \\
\hline 7 & Manageability & Structural \\
\hline 8 & Management Style & Behavioral \\
\hline 9 & Action Orientation & Behavioral \\
\hline
\end{tabular}

It is clear from Table 4 that the PMA dimension Accountability has the strongest positive effect on creating and maintaining a HPO. This is in line with the outcomes as reported by many authors who found a positive relationship between accountability and performance (e.g., GAO, 2005; Hochwarter et al., 2007; Marsh, 2010; Wunsche, 2007). For each of the other HPO factors, there is a different order of impact of the PMA dimensions. This undoubtedly has to do with the specific nature of each HPO factor. It is interesting to note that the behavioral dimensions "bracket" the structural dimensions of the performance management system. It seems clear that certain behavioral aspects of the people in the organization are decisive for creating high performance, but this behavior has to be rooted in a robust performance management structure.

When an organization pays attention to strengthening the PMA dimensions, the HPO factors will be strengthened as well, helping to improve the organization's overall results. To illustrate, Table 3 has been depicted schematically (see Figure 1). This figure shows relationships among the dimensions of performance management, factors of high-performance organizations, and overall organizational performance. The relationships shown between the PMA dimensions and the HPO factors originate from research done by de Waal (2012). This schematic constitutes a first and important step in opening the aforementioned "black box" of performance management and sheds light on the process through which a performance management system affects overall organizational performance (Pavlov \& Bourne, 2011). 


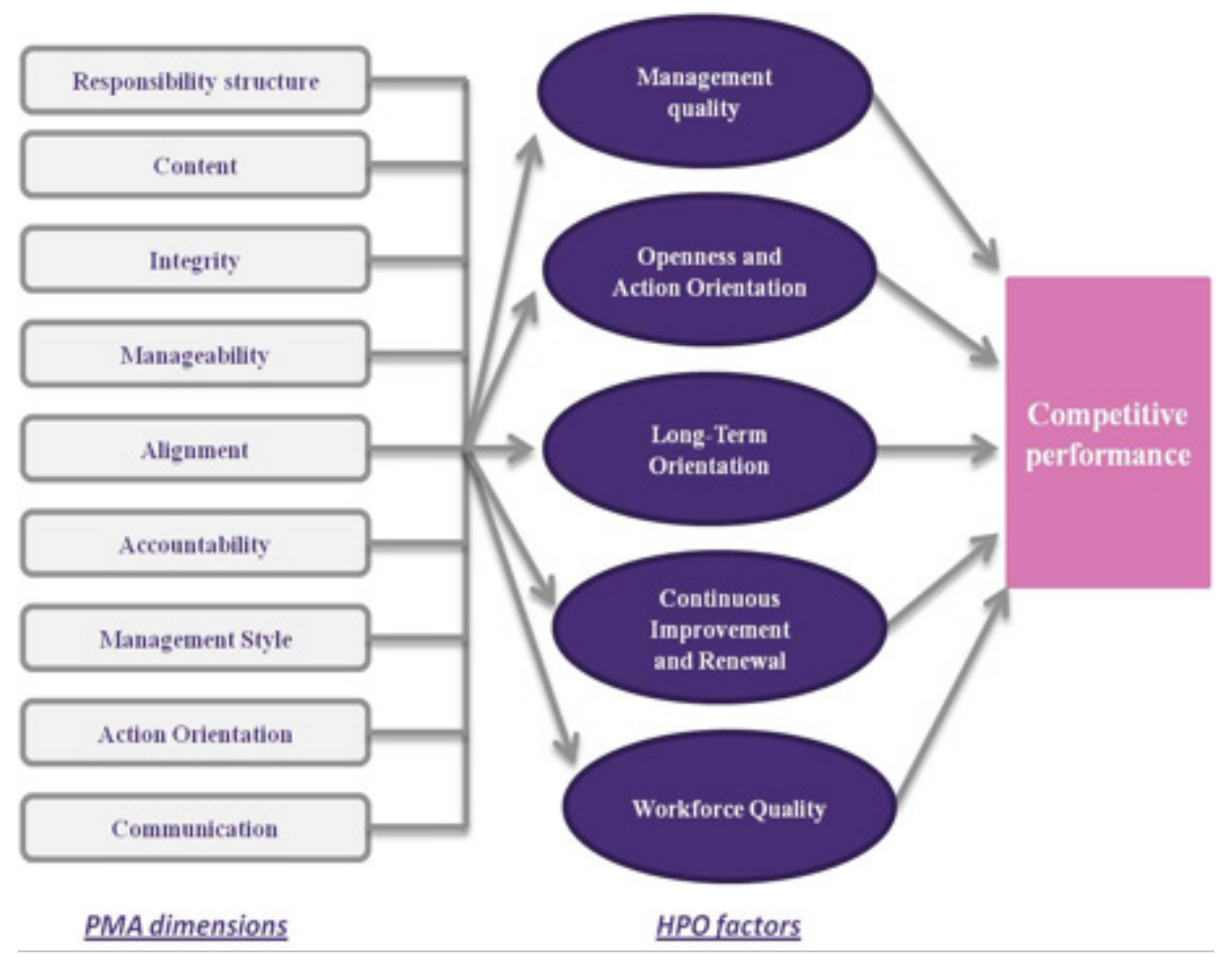

Fig. 1. Relationships Among the PMA Dimensions, HPO Factors, and Organizational Performance

\section{STUDY LIMITATIONS AND FUTURE RESEARCH}

An important limitation of this study is that only two for-profit companies, both of which operate in different industries in the Western world and comprise large cooperations, have been investigated. This means that future research is needed that focuses on empirically investigating the performance systems in use in organizations in various industries, including the non-profit and governmental sectors, in order to evaluate how they support the high-performance organization. Other opportunities include studying whether there is a relationship between performance management and HPO in a non-European context, and whether this relationship exists for small and medium-size companies as well. A final limitation is that we cannot rule out endogeneity and therefore cannot answer the issue of causality: does the use of performance management help to create an HPO, or is an HPO in a better position to implement performance management? Much literature in the field of performance management suggests that its application does help to improve the results of an organization and, as such, helps to create HPO. Therefore, in Figure 1, we have put the PMA dimensions before the HPO factors. However, further research is needed to gain more insight into the direction of causality.

\section{CONCLUSION}

Now that the correlational pattern between PMA and HPO has been established, an organization knows which dimensions of its performance management system positively affect organizational success and therefore have to be strengthened. Moreover, based on the findings of our study, there is more insight into the order in which the PMA dimensions have to be improved in order to optimize the chance to strengthen specific HPO factors. Our study contributes to the literature in that the characteristics of a performance management system have now been correlated with the factors of high performance. This makes it possible for practitioners to work in a more systematic and targeted manner on improving the organization's performance management system and thus on strengthening the organization. 


\section{REFERENCES}

Brudan A. 2010. Rediscovering performance management: Systems, learning and integration. Measuring Business Excellence 14(1): 109-123.

Choong KK. 2014. The fundamentals of performance measurement systems. International Journal of Productivity and Performance Management 63(7): 879-922.

de Waal AA. 2010. Performance-driven behavior as the key to improved organizational performance. Measuring Business Excellence 14(1): 79-95.

de Waal AA. 2012. What Makes a High Performance Organization: Five Factors of Competitive Advantage that Apply Worldwide. Global Professional Publishing, London, England.

de Waal AA, Kourtit K. 2013. Performance measurement and management in practice: Advantages, disadvantages and reasons for use. International Journal of Productivity and Performance Management 62(5): 446-473.

de Waal AA, Orij R, Rosman J, Zevenbergen M. 2014. Applicability of the high-performance organization framework in the diamond industry value chain. Journal of Strategy and Management 7(1): 30-48.

Elzinga T, Albronda B, Kluijtmans F. 2009. Behavioral factors influencing performance management systems' use. International Journal of Productivity and Performance Management 58(6): 508-522.

GAO. 2005. Diversity Management: Expert-Identified Leading Practices and Agency Examples. United States Government Accountability Office, GAO Report 05-90, Washington, DC.

Hochwarter WA, Ferris GR, Gavin MB, Perrewé PL, Hall AT, Frink DD. 2007. Political skill as neutralizer of felt accountability--job tension effects on job performance ratings: A longitudinal investigation. Organizational Behavior and Human Decision Processes 102(2): 226-239.

Kaplan RS, Norton DP. 1996. The Balanced Scorecard: Translating Strategy into Action. Harvard Business School Press, Boston, MA.

Marsh FK. 2010. High performance team: Building a business program with part- and fulltime faculty. Journal of Education for Business 85(4): 187-194.

Neely AD. 2005. The evolution of performance measurement research: Developments in the last decade and a research agenda for the next. International Journal of Operations and Production Management 25(12): 1264-1277.

Pavlov A, Bourne M. 2011. Explaining the effects of performance measurement on performance - an organizational routines perspective. International Journal of Operations and Production Management 31(1): 101-122.

Rangone A. 1997. Linking organizational effectiveness, key success factors and performance measures: An analytical framework. Management Accounting Research 8(2): 207-219.

Taticchi P, Balachandran K, Tonelli F. 2012. Performance measurement and management systems: State of the art, guidelines for design and challenges. Measuring Business Excellence 16(2): 41-54.

Wunsche A. 2007. The CFO as strategist and catalyst in building a high-performance culture. Ivey Business Journal 71(8): 1-10.

\section{ANDRÉ A. DE WAAL}

Center for Organizational Performance, Hilversum, The Netherlands

Maastricht School of Management, Maastricht, The Netherlands

E-mail: andredewaal@planet.nl

\section{BÉATRICE I.J.M. VAN DER HEIJDEN}

Institute for Management Research, Radboud University, Nijmegen, The Netherlands

Open University of the Netherlands

E-mail: b.vanderheijden@fm.ru.nl 


\section{APPENDIX 1. THE PERFORMANCE MANAGEMENT ANALYSIS}

In this Appendix, the nine dimensions and 44 characteristics of the PMA are listed.

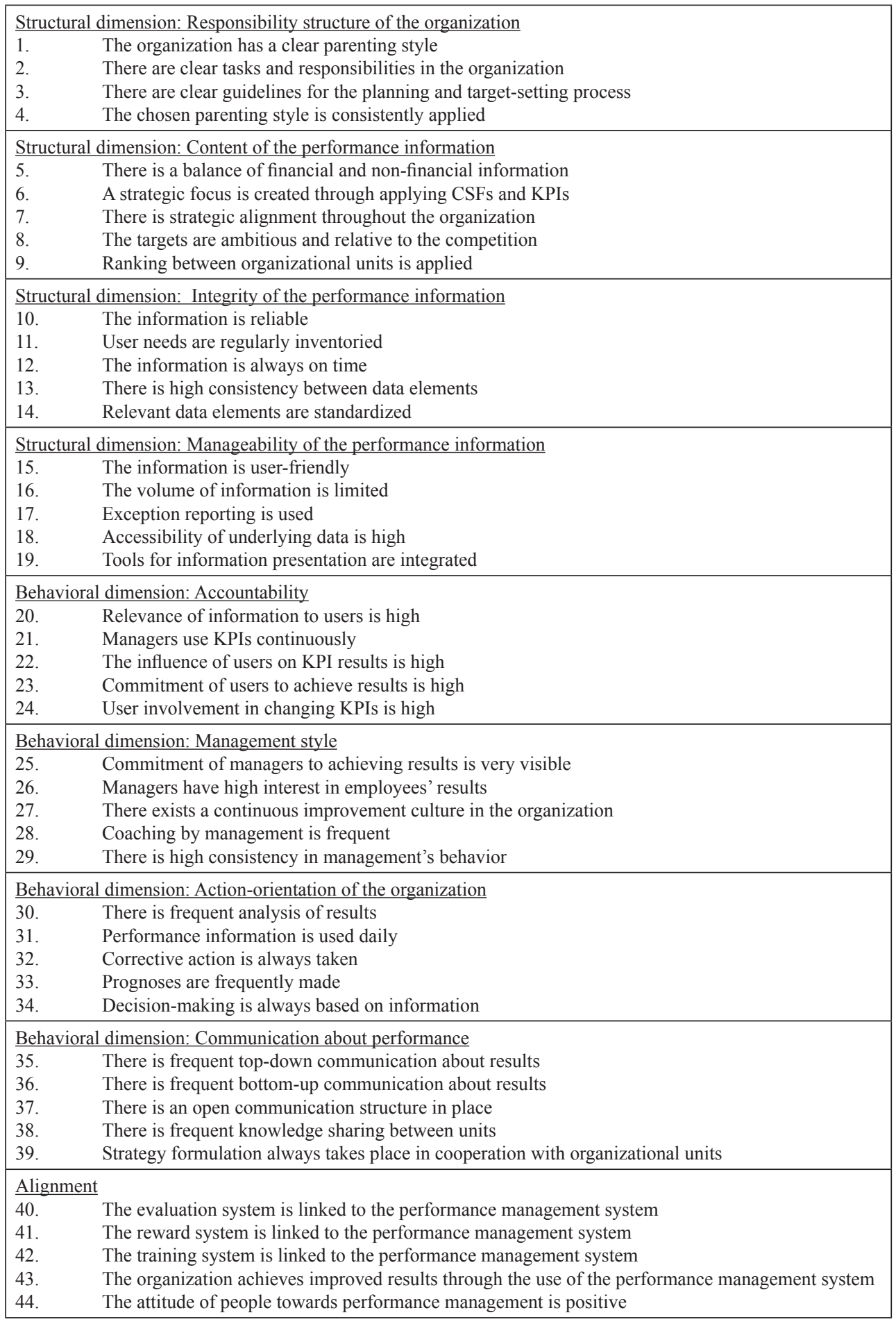




\section{APPENDIX 2. THE HPO FRAMEWORK}

In this Appendix, the five HPO factors and their 35 characteristics are listed.

\begin{tabular}{|c|c|}
\hline & HPO FACTORS AND CHARACTERISTICS \\
\hline $\begin{array}{l}\text { Continuou } \\
1 . \\
2 . \\
3 . \\
4 . \\
5 . \\
6 . \\
\text { members. } \\
7 . \\
8 .\end{array}$ & $\begin{array}{l}\text { Improvement and Renewal } \\
\text { The organization has adopted a strategy that sets it clearly apart from other organizations. } \\
\text { In the organization, processes are continuously improved. } \\
\text { In the organization, processes are continuously simplified. } \\
\text { In the organization, processes are continuously aligned. } \\
\text { In the organization, everything that matters to performance is explicitly reported. } \\
\text { In the organization, both financial and non-financial information is reported to organizational } \\
\text { The organization continuously innovates its core competencies. } \\
\text { The organization continuously innovates its products, processes and services. }\end{array}$ \\
\hline $\begin{array}{l}\text { Openness } \\
9 . \\
10 . \\
11 . \\
12 . \\
13 . \\
14 .\end{array}$ & $\begin{array}{l}\text { and Action-Orientation } \\
\text { Management frequently engages in a dialogue with employees. } \\
\text { Organizational members spend much time on communication, knowledge exchange and learning. } \\
\text { Organizational members are always involved in important processes. } \\
\text { Management allows making mistakes. } \\
\text { Management welcomes change. } \\
\text { The organization is performance driven. }\end{array}$ \\
\hline $\begin{array}{l}\text { Manageme } \\
15 . \\
16 . \\
17 . \\
18 . \\
19 . \\
20 . \\
21 . \\
22 . \\
23 \text {. } \\
24 . \\
25 \text {. } \\
26 .\end{array}$ & $\begin{array}{l}\text { Muality } \\
\text { Management is trusted by organization members. } \\
\text { Management has integrity. } \\
\text { Management is a role model for organization members. } \\
\text { Management applies fast decision-making. } \\
\text { Management applies fast action-taking. } \\
\text { Management coaches organization members to achieve exceptional results. } \\
\text { Management focuses on achieving results. } \\
\text { Management is very effective. } \\
\text { Management applies strong leadership. } \\
\text { Management is confident. } \\
\text { Management is decisive with regard to non-performers. } \\
\text { Management always holds organization members responsible for their results }\end{array}$ \\
\hline $\begin{array}{l}\text { Workforce } \\
27 . \\
28 . \\
29 . \\
30 .\end{array}$ & $\begin{array}{l}\text { Quality } \\
\text { Management inspires organization members to accomplish extraordinary results. } \\
\text { Organization members are trained to be resilient and flexible. } \\
\text { The organization has a diverse and complementary workforce. } \\
\text { The organization grows through partnerships with suppliers and/or customers. }\end{array}$ \\
\hline $\begin{array}{l}\text { Long-Ter } \\
31 . \\
32 . \\
33 . \\
34 . \\
35 .\end{array}$ & $\begin{array}{l}\text { n Orientation } \\
\text { The organization maintains good and long-term relationships with all stakeholders. } \\
\text { The organization is aimed at servicing customers as best as possible. } \\
\text { Management has been with the company for a long time. } \\
\text { New management is promoted from within the organization. } \\
\text { The organization is a secure workplace for organization members. }\end{array}$ \\
\hline
\end{tabular}

